Pacific Journal of Mathematics

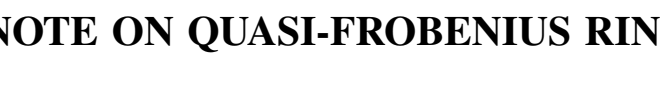




\title{
A NOTE ON QUASI-FROBENIUS RINGS
}

\author{
EDGAR ENOCHS
}

\begin{abstract}
Morita and Curtis proved independently that if $A$ is a quasi-Frobenius ring and $P_{a}^{\vee}$ finitely generated, projective, faithful, left $A$-module, then the ring of endomorphisms $B=\operatorname{End}_{A}(P)$ is quasi-Frobenius and $P$ is a finitely generated, projective, faithful, left $B$-module. It also turns out that $A \cong \operatorname{End}_{B}(P)$. We prove a theorem implying that every quasi-Frobenius ring can be represented as such a ring of endomorphisms.
\end{abstract}

In fact the following holds:

THEOREM. If $A$ is a quasi-Frobenius ring there is a Frobenius ring $B$ such that $B / \operatorname{Rad}(B)$ is the product of a finite number of (not necessarily commutative) fields and a finitely generated, projective, faithful, left $B$-module $P$ such that $A \cong \operatorname{End}_{B}(P)$. If $B^{\prime}$ if another Frobenius ring such that $B^{\prime} / \operatorname{Rad}\left(B^{\prime}\right)$ is the product of a finite number of fields and $P^{\prime}$ a finitely generated, projective, faithful, left $B^{\prime}$-module such that $A \cong \operatorname{End}_{B^{\prime}}(P)$ then there is a semilinear isomorphism of the $B$-module $P$ into the $B^{\prime}$-module $P^{\prime}$.

We note the results mentioned above appear in [2, pp. 405-406].

Proof. Let $A_{s}$ be $A$ considered as a left $A$-module. Let $A_{s}=$ $E_{1}+\cdots+E_{n}$ (direct) where each $E_{i}$ is nonzero and indecomposable, and so has a simple socle. Consider the equivalence relation $E_{i} \cong E_{j}$ on the set $\left\{E_{1}, E_{2}, \cdots, E_{n}\right\}$. Note $E_{i} \cong E_{j}$ if and only if $S_{i} \cong S_{j}$ where $S_{i}$ is the socle of $E_{i}$ for each $i$. Choose one representative from each equivalence class and let $P$ be their direct sum. Then we easily see that $P$ is a finitely generated, projective, faithful, left $A$-module. Let $B=\operatorname{End}_{A}(P)$. Then by Morita and Curtis' result, $B$ is a quasiFrobenius ring and $P$ is a finitely generated, projective, faithful, left $B$-module. We claim that if we show $B / \operatorname{Rad}(B)$ is the product of a finite number of fields then it will follow that $B$ is Frobenius. For in this case $B / \operatorname{Rad}(B)$ is the direct sum of a finite number of simple pair-wise nonisomorphic left $B$-modules. But since $B$ is quasi-Frobenius each simple left $B$-module is isomorphic to a submodule of $B[2, \mathrm{p}$. 401, Corollary 58.13]. But to show $B / \operatorname{Rad}(B)$ is a product of fields we only need note that $B / \operatorname{Rad}(B) \cong \operatorname{End}_{A}(T)$ where $T$ is the socle of $P$. But by the construction of $P, T$ is the direct sum of a finite number of pair-wise nonisomorphic simple left $A$-modules so $\operatorname{End}_{A}(T)$ is the 
product of a finite number of fields. But now as remarked above, $A \cong \operatorname{End}_{B}(P)$ and $P$ is a finitely generated, projective, faithful, left $B$-module.

Now suppose $A \cong \operatorname{End}_{B^{\prime}}\left(P^{\prime}\right)$ where $B^{\prime}$ is a Frobenius ring with $B^{\prime} / \operatorname{Rad}\left(B^{\prime}\right)$ the product of a finite number of fields and that $P^{\prime}$ is a finitely generated, projective, faithful, left $B^{\prime}$-module. Then $P^{\prime}$ is a finitely generated, projective, faithful, left $A$-module and $B^{\prime} \cong \operatorname{End}_{A}\left(P^{\prime}\right)$. But then since $A$ is quasi-Frobenius, $P^{\prime} \cong \bigoplus_{i=1}^{m} E_{k_{i}}$ where $1 \leqq k_{i} \leqq n$ for each $i=1,2, \cdots, m$ [2, p. 401, Corollary 58.13]. But $P^{\prime}$ is a faithful left $A$-module so it's easy to see that for each $j, 1 \leqq j \leqq n$, $E_{k i} \cong E_{j}$ for some $i, 1 \leqq i \leqq m$. But now if $T^{\prime}$ is the socle of $P^{\prime}$ (as a left $A$-module), $B^{\prime} / \operatorname{Rad}\left(B^{\prime}\right) \cong \operatorname{End}_{A}\left(T^{\prime}\right)$. But $B^{\prime} / \operatorname{Rad}\left(B^{\prime}\right)$ is the product of a finite number of fields so we see that $T^{\prime}$ is the direct sum of a finite number of pair-wise nonisomorphic simple left $A$-modules. Thus $P \cong P^{\prime}$ (as left $A$-modules). But then

$$
B \cong \operatorname{End}_{A}(P) \cong \operatorname{End}_{A}\left(P^{\prime}\right) \cong B^{\prime} \text { and }
$$

we easily see that there is a semi-linear isomorphism from the $B$-module $P$ to the $B^{\prime}$-module $P^{\prime}$.

We note that if $A$ is a simple ring (i.e. left Artinian, without radical and having no nontrivial two sided ideals) we get the usual representation of $A$ as the ring of matrices over a field (i.e. the endomorphism ring of a finite dimensional vector space) since in this case $B$ is a field.

\section{BIBLIOGRAPHY}

1. C. W. Curtis, Quasi-Frobenius rings and Galois theory, Illinois J. Math. 3 (1959), 134-144.

2. C. W. Curtis and I. Reiner, Representation Theory of Finite Groups and Associative Algebras, Interscience Publishers, New York, New York. 1962.

3. K. Morita, Duality for modules and its applications to the theory of rings with minimum condition, Science reports of the Tokyo Kyoiku Daigaku, 6 (1958), 83-142.

Received February 28, 1967.

University of South Carolina

Columbia, South Carolina 


\section{PACIFIC JOURNAL OF MATHEMATICS}

\section{EDITORS}

\section{H. ROYDEN}

Stanford University

Stanford, California

\section{J. P. Jans}

University of Washington

Seattle, Washington 98105

\section{J. DUGUNDJI}

Department of Mathematics

Rice University

Houston, Texas 77001

RICHARD ARENS

University of California

Los Angeles, California 90024

\section{ASSOCIATE EDITORS}
E. F. BeCKenbaCH
B. H. NeumanN
F. WOLF
K. YosIDA

\section{SUPPORTING INSTITUTIONS}

UNIVERSITY OF BRITISH COLUMBIA CALIFORNIA INSTITUTE OF TECHNOLOGY UNIVERSITY OF CALIFORNIA MONTANA STATE UNIVERSITY UNIVERSITY OF NEVADA NEW MEXICO STATE UNIVERSITY OREGON STATE UNIVERSITY UNIVERSITY OF OREGON OSAKA UNIVERSITY UNIVERSITY OF SOUTHERN CALIFORNIA
STANFORD UNIVERSITY UNIVERSITY OF TOKYO UNIVERSITY OF UTAH WASHINGTON STATE UNIVERSITY UNIVERSITY OF WASHINGTON

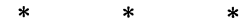

AMERICAN MATHEMATICAL SOCIETY CHEVRON RESEARCH CORPORATION TRW SYSTEMS

NAVAL ORDNANCE TEST STATION 


\section{Pacific Journal of Mathematics}

\section{Vol. 24, No. $1 \quad$ May, 1968}

Harry P. Allen, Lie algebras of type $D_{4}$ over algebraic number fields ...... 1

Charles Ballantine, Products of positive definite matrices. II............ 7

David W. Boyd, The spectral radius of averaging operators ............ 19

William Howard Caldwell, Hypercyclic rings ................... 29

Francis William Carroll, Some properties of sequences, with an application

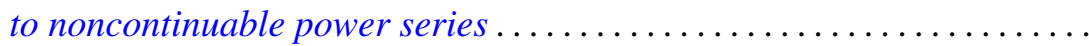

David Fleming Dawson, Matrix summability over certain classes of

sequences ordered with respect to rate of convergence ........... 51

D. W. Dubois, Second note on David Harrison's theory of preprimes. . . . . 57

Edgar Earle Enochs, A note on quasi-Frobenius rings.............. 69

Ronald J. Ensey, Isomorphism invariants for Abelian groups modulo bounded groups ................................ 71

Ronald Owen Fulp, Generalized semigroup kernels ................ 93

Bernard Robert Kripke and Richard Bruce Holmes, Interposition and approximation ................................. 103

Jack W. Macki and James Sai-Wing Wong, Oscillation of solutions to second-order nonlinear differential equations ..................

Lothrop Mittenthal, Operator valued analytic functions and generalizations

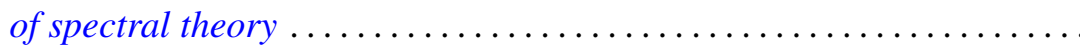

T. S. Motzkin and J. L. Walsh, A persistent local maximum of the pth power deviation on an interval, $p<1 \ldots \ldots \ldots \ldots \ldots \ldots \ldots \ldots \ldots \ldots . \ldots \ldots$

Jerome L. Paul, Sequences of homeomorphisms which converge to homeomorphisms ...........................

Maxwell Alexander Rosenlicht, Liouville's theorem on functions with elementary integrals.

Joseph Goeffrey Rosenstein, Initial segments of degrees .

$\mathrm{H}$. Subramanian, Ideal neighbourhoods in a ring ............

Dalton Tarwater, Galois cohomology of abelian groups . .

James Patrick Williams, Schwarz norms for operators ... .

Raymond Y. T. Wong, A wild Cantor set in the Hilbert cube. 